bullet wounds, and more wounds from shell fragments than shrapnel. All shell wounds were septic. A small proportion of the penetrating bullet wounds of soft parts were of the South African typei.e., clean, with small entry and exit and without intermediate laceration from axial rotation of the bullet; the majority were septic with intermediate laceration and irregular exit. In the non-explosive wounds injuries to the main vessels and nerves seem to be rare. Simple penetrating bone wounds are unknown, and the comminuted fractures are far worse both in extent and as regards sepsis. Penetrating wounds of the brain seldom reach the base, but gutter fractures (and in every case bone fragments are driven inwards) of the skull are quite common. More recently, as the result of increased entrenchment and siege warfare, bullet wounds have increased in their proportion to shell wounds. The clean penetrating and non-explosive wounds have, so far as I have seen, always been produced at short range. At longer ranges apparently the slightest deviation of impact from the normal to the surface results in rotation of the bullet on its transverse axis as it impinges, followed by churning up of the soft parts with laceration of the skin at exit. At very long ranges this same condition may be observed and confirmed by the retention of the bullet. The comparative frequency of gutter fractures of the skull is probably also explained by impact deviation. The difference between the wounds of soft parts here and in South Africa is doubtless due to the pointed bullet with its centre of gravity near the base as opposed to the dome-shaped Mauser bullet with its centre of gravity near the middle. It seems possible that the pointed bullet (when it does not rotate and lacerate) pushes its way past the main vessels and nerves rather than cutsits way through with injury to vessel and nerve. In other instances it will, as I have seen, penetrate a nerve of smaller diameter than itself and leave the continuity of the nerve intact, which would not be possible with the Mauser bullet. In the case referred to the bullet passed through the outer head of the median and the posterior cord of the brachial plexus without severing the nerves (though producing paralysis).

As regards sepsis, Sir A. Bowlby makes it clear that it is the highly fertilised soil as opposed to the sun-dried veld dust, trench warfare as opposed to skirmishing at long range, and the preponderance of devastating gun fire over rifle fire, which are the determining factors rather than the surgery or want of surgery at the front.

As regards the infection, apart from anaerobes, streptococcal and coli infections are fairly common; an initial staphylococcal infection is rare.

I am, Sir, yours faithfully,

C. GORDON WATSON.

Duchess of Westminster Hospital, Le Touquet, Dec. 24th, 1914.

\section{ALCOHOL AND THE WAR.}

\section{To the Editor of THE LANCET.}

SIR,-You were good enough to publish in your issue of Nov. 21st, 1914, an account of the conference which took place on Nov. 12th, under the presidency of His Grace the Archbishop of Canterbury, to consider the subject of alcohol and the war. Since then I have been appointed honorary secretary of the Central Emergency Committee which was formed by the conference in order to secure the carrying out of the resolutions which were passed by that influential gathering. It should be remem. bered that the conference was called together in order to support Lord Kitchener's appeal to the nation, issued through the Press Bureau, asking that the public should "help the soldiers," and especially urging that steps should be taken to educate public opinion in this matter. It is clear that Lord Kitchener had in his mind something beyond the ordinary risks which are associated with alcoholism, and when we refer to his message to the troops at the outset of the war we find that he warned them against the temptations connected with "wine and women," and said, "You must entirely resist both temptations." Major Darwin, as an old soldier and as one who has interested himself in the many difficult problems which bear upon the health and well-being of the nation, referred in his speech at the conference to the appalling connexion between alcohol and venereal disease and the special conditions which had been created by the war, including the crowding together of large masses of men in centres unaccustomed to receive them.

This is but one aspect of a great question, but I mention it because I consider that a grave responsibility rests upon the medical profession in this matter. That the profession is rising and will rise to the occasion I do not doubt for a moment, and the speeches of Sir Thomas Barlow and Sir $T$. Clifford Allbutt at the conference as already reported by you were of the greatest value. I venture, how. ever, to appeal earnestly to medical men and medical women throughout our land to join in giving that support to Lord Kitchener's appeal which is needed at this moment. Every lord mayor and mayor, and chairmen of district councils have received an appeal from the Central Emergency Committee to take part in this movement in the hope that local emergency committees will be formed in each locality to ensure that the nation may respond to the call which comes to them to assist in promoting the utmost efficiency of all classes at this critical time.-I am, Sir, yours faithfully,

Charles F. Harford, M.D. Cantab., Honorary Secretary, Central Emergency Committee. Paternoster House, E.C.. Dec. 21st, 1914 .

\section{ANTISEPTIC TREATMENT OF WOUNDS.}

To the Editor of THE LANCET.

SIR,-I have followed with great interest and instruction the various contributions to THE LANCET on the treatment of septic wounds, and although it is needless to say that the question of wounds in war is at the moment of paramount importance and interest, I feel there is an aspect of the question relating to both wounds in war and civil life which at any rate has not been settled by your correspondents. I refer to the place of iodine as an antiseptic. Iodine in alcohol as the ordinary tincture or in 2 per cent. solution-is it or is it not an effective destroyer of organisms and their spores?

I am perfectly well aware that Sir Watson Cheyne says it is not; that he says, indeed, it is the equivalent of only a 1 in 50 solution of phenol. Naturally I regard this considered pronouncement of so distinguished a surgeon with the greatest respect, but I venture to suggest that if this knowledge is shared by many of his colleagues it is certainly ignored.

Take, for example, the gynæcologist who uses it and swabs out the interior of a uterus which has been the source of an endless discharge; or Sir Anthony Bowlby, whose practice it is "to paint the skin far around with 2 per cent. iodine in spirit"; 